\title{
Microprocessors and the printed word
}

There is now a chance that the coming decade will see the flowering of the revolution in communications that the prophets of technology have foretold since the end of the Second World War. Microprocessors, distributed computer facilities and the like offer powerful ways of storing and handling information. Novel kinds of communications channels promise widespread access, flexibility and low cost. Means of turning electronic representations of information into forms that can be read by human eyes and processed by human nervous systems become more versatile as the years go by. The chances that these devices will be welded fruitfully together in the 1980 s are greater than in previous decades. It is, of course, far too soon to be certain how the decade will turn out. A severe and probably prolonged economic recession throughout the industrialized West is hardly the best time for launching a major revolution of technology. Lack of capital may yet frustrate the plans being laid for the new communications technology. Yet it is only prudent that people should be asking what will be the consequences of the promised changes. Already there is a vigorous if somewhat shapeless debate about the consequences for employment: will there be more of it, or less? That argument is likely to grumble on, unresolved, for many years to come. What of more specific questions such as the consequences of the new technology for communication in science and technology? In particular, are the days of the conventional journals numbered?

This is one of the questions raised by a study, now published, carried out by the Primary Communications Research Centre at the University of Leicester. (New technology and developments in the communication of research during the 1980s, obtainable from the centre at $£ 2.50$ within the UK, $£ 3.00$ elsewhere.) For what it is worth, the report of the study appears on ordinary paper. The type has been set by pointing cameras at sheets of typewritten paper. Distribution is conventional, by post. Clearly those who pave the way for revolutions must conduct themselves conventionally for a time, as John the Baptist discovered to his cost.

Indeed, the report of the Leicester group, led by Professor Jack Meadows, is largely a sketch of what the future may bring in the communication of information in science and technology. It is a survey of the options that may open up, not a prescription for a preferred course of development. That, too, is seemly. For in the end, the ways in which scientists communicate with each other will be determined by what they want to do.

It is not, however, too soon to think of what the future may be like. The most radical revolution of the scientific literature rejoices in the name of the "electronic journal". The idea is simple. Somewhere there is a computer system capable of storing scientific articles together with the data, in tabular form, as graphs and photographs. People wishing to submit articles for "publication" merely arrange that the text of their contribution is fed into the system. At some stage, human editors must intervene, if only to decide which scientists in which laboratories should be invited to referee which articles, but from that point the process of publication is more or less mechanical. Referees' comments come and go by the same communications system. Authors are invited to amend their manuscripts, and the revised versions are in due course listed in the public file of articles to which all and sundry may have access. Reading a journal will then be simply a process of pressing an appropriate button on a communications terminal to summon up the latest table of contents and then to display whatever articles may be of particular interest.

This version of the future has a number of attractive features. In principle, it is capable of great flexibility. Some readers of some electronic journals might wish to read the abstracts of all the articles on the file, and could no doubt be satisfied by pressing a few extra buttons - and for an extra charge. The editors of some journals might decide that articles should be available on the network before they have been refereed, so that readers could share with authors the experience of seeing articles take their final form. Some visionaries even dream of schemes in which the whole of some group of interested specialists would be involved in the assessment of each individual's contributions to the literature. The result might be a much greater sense of community, and that the literature of some field of research is truly the collective understanding and the common heritage of those working in it. Such schemes are by no means as fanciful as they sound. Some of the more interesting of the journals in the conventional scientific literature are those in which each article is accompanied by a string of written comments from others with useful things to say about them.

More modest benefits of electronic journals are probably more nearly within grasp. Plainly, there would be great advantages if the same network could provide its users not merely with versions (printed, or electronic) of articles of interest but also with copies of articles cited in the list of references. The utility of such a system will depend critically on the degree to which the literature as a whole accumulates in electronic form. Searches of the electronic literature for relevant contributions not included in the cited references would also be valuable. Electronic versions of the primary journals could be combined in the same network with more advanced versions of the bibliographic files of titles and abstracts that have made a modest contribution to many people's awareness of the scientific literature in the past decade or so. This, however, is yet another benefit that will accrue only when the process of making the literature electronic has absorbed a substantial part of the whole.

The disadvantages of this way of organizing the scientific literature are, unfortunately, less easily identified. Although it is now customary to suppose that computer technology can be adapted to any task whose specification can be defined, experience has shown that computer systems do not always function as smoothly as their designers hope. The development of computer systems which are acceptable to the users of electronic journals, and not just to their designers and editors, will be slow and expensive. The costs of operating and using electronic journals cannot even be guessed at this early stage. The most obvious difficulty is that the initial costs are certain to be very large. Would-be users will have to equip themselves with communications terminals at a cost that far exceeds the annual subscription to even the most high-priced journals.

Even less tangible disadvantages may be more serious impediments to these developments. Even within the scientific community, people are conservative in their habits. Browsing through the scientific literature, not necessarily in a single narrow field, is not merely pleasurable but educative and stimulating. Will the communications terminals of the future lend themselves to such a practice? But people also appear to like carrying their favourite journals around with them, reading them at home or on some journey. Will a sheaf of hard-copy paper produced by a communications terminal serve the same purpose? People are, in short, attached to the printed word in its familiar form. Those who are now planning electronic journals are no doubt aware of the subtlety of the needs they have to satisfy. Defining them, however, will be a formidable undertaking. Experience may yet show that they cannot be met. 